\title{
DIREITO E CASUÍSMO: O PROBLEMA DA IRRACIONALIDADE NAS DECISÕES JUDICIAIS
}

LAW AND CASUISM: THE PROBLEM OF IRRATIONALITY IN JUDICIAL DECISIONS DERECHO Y CASUISMO: EL PROBLEMA DE LA IRRACIONALIDAD EN LAS DECISIONES JUDICIALES

\section{Fabiano Hartmann Peixoto ${ }^{1}$}

Licença CC BY: Artigo distribuído sob os termos Creative Commons, permite uso e distribuição irrestrita em qualquer meio desde que o autor credite a fonte original.

\section{(c) (1)}

Resumo: Convergir direito e justiça e aceitar que o que é injusto não é direito impõem uma reflexão sobre o problema do casuísmo. O casuísmo viola regras condizentes com a perspectiva de justiça dos julgamentos, contudo há uma linha tênue entre as perspectivas concretas e consequencialistas que, de alguma maneira, orientam a decisão e a impossibilidade de atendimento de regras básicas do discurso em sua perspectiva de universabilidade. Utilizandose o método dedutivo, o presente artigo buscará a compreensão, dentro do universo da argumentação jurídica, das relações entre o direito e o problema do casuísmo das decisões judiciais. Para atingir o objetivo citado, o presente trabalho abordará elementos teóricos apresentados por Manuel Atienza e Robert Alexy, que identificam o campo da argumentação jurídica e as possibilidades de contribuição dela com o direito em suas perspectivas formal e substancial.

Palavras-chave: Argumentação Jurídica - racionalidade - correção -decisão.

Abstract: When law and justice converge and accept that what is unjust is not legal, it imposes a reflection on the problem of casuism. Casuistry violates rules that are consistent with the fairness of judgments, but there is a fine line between concrete and consequentialist perspectives that somehow guide the decision and the impossibility of meeting basic rules of discourse in its perspective of universability. Using the deductive method, this article aims to understand, within the universe of legal argumentation, the relations between the law and the problem of casuistry of judicial decisions. To achieve this, it addresses the theoretical elements presented by Manuel Atienza and Robert Alexy, who identify the field of legal argumentation and the possibilities of its contribution to the law in its formal and substantial perspectives.

1 Doutor em Direito pela UnB (Capes 6), Mestre em ciência jurídica pela Univali, Professor permanente da Faculdade de Direito e do PPGD da Universidade de Brasília. Brasília/DF. E-mail: fabiano_hp@hotmail.com. 
Resumen: Converger derecho y justicia y aceptar que lo que es injusto no es derecho impone una reflexión sobre el problema del casuismo. El casuismo viola reglas condicentes con la perspectiva de justicia de los juicios, sin embargo, hay una línea tenue entre las perspectivas concretas y consecuenciales que, de alguna manera, orientan la decisión y la imposibilidad de atención de reglas básicas del discurso en su perspectiva de universalidad. Utilizándose el método deductivo, el presente artículo buscará la comprensión, dentro del universo de la argumentación jurídica, de las relaciones entre el derecho y el problema del casuismo de las decisiones judiciales. Para alcanzar el objetivo citado, el presente trabajo abordará elementos teóricos presentados por Manuel Atienza y Robert Alexy, que identifican el campo de la argumentación jurídica y las posibilidades de contribución de ella con el derecho en sus perspectivas formal y substancial.

Palabras-clave: Argumentación Jurídica - racionalidad - corrección - decisión.

\section{INTRODUÇÃO}

Casuísmo não é justo! O que não é justo, não é direito! Destas duas premissas, longe de serem petições de princípio, muito mais próximos a topoi da teoria do direito lato sensu, impõe-se que no marco filosófico do pós-positivismo há uma complexa demanda colocada à Teoria do Direito sobre as decisões judiciais. Decisões casuísticas podem/devem ser consideradas antijurídicas numa perspectiva substancial. Ao se adotar uma visão diferenciada do direito que a do formalismo jurídico, uma das críticas mais fortes que se recebe é a possibilidade que se dá ao responsável pela decisão judicial realizar uma hermenêutica própria, discricionária e influenciável ${ }^{2}$. Com isto a segurança jurídica e as bases do estado de direito entrariam em um estado vegetativo. Com o incremento das nuances plurais e polivalorativas da sociedade e a incidência, cada vez mais frequente, de normasfim na atividade do julgador, por outro lado, uma regra básica discursiva, apontada pelos princípios da universalidade e da igualdade, também é constantemente colocada em posição paradoxal. Os elementos valorativos também se impõem na aplicação do direito, sob pena do esvaziamento do significado do próprio e seu descolamento da fonte social. A visão pós-positivista também pode fornecer respostas às inquietudes das teses da salvaguarda ${ }^{3}$.

2 A discussão acerca dos limites da interferência judicial em decisões políticas vai muito além da esfera das políticas públicas e remete à engenharia jurídico-institucional do controle judicial de constitucionalidade. De fato, ampla e sólida argumentação jurídica foi construída para sustentar a legitimidade da interferência judicial na atuação dos poderes representativos do Estado. CAVALCANTI, Ana Beatriz Vanzoff Robalinho; MACHADO, Bruno Amaral.. Democracia e os paradoxos da judicialização das políticas públicas de saúde no Brasil. Revista Novos Estudos Jurídicos/ UNIVALI. Volume 22 - № 2 - $2^{\circ}$ Quadrimestre de 2017, p. 634. DOI: http://dx.doi.org/10.14210/nej.v22n2.p624-652.

3 O presente trabalho é parte de uma série de pesquisas do autor no âmbito da argumentação jurídica, com objetivos de melhor entendimento sobre argumento, argumentação, justificação das decisões, ponderação, racionalidade e controle de decisões judiciais. 


\section{ARGUMENTAÇÃO E (IR)RACIONALIDADE}

Em sua obra Conceito e validade do Direito, Alexy ${ }^{4}$ faz uma distinção sobre o problema conceitual do Direito em perspectiva entre a moral e o Direito: a tese da separação (fundamental para as teses positivistas), na qual a preocupação está na conformidade com o ordenamento e na eficácia social, e a tese da vinculação (fundamental para as teses não positivistas), na qual o conceito de Direito deve levar em conta elementos morais. A tese da vinculação não exclui as duas preocupações da tese da separação (conformidade com o ordenamento e a eficácia), mas os observa a partir de uma ótica de correção.

Essa ótica de correção é ilustrada por Alexy ${ }^{5}$ com o exemplo do "injusto legal - não direito" da decisão sobre cidadania do Tribunal Constitucional Federal. Nessa decisão, o Tribunal considerou uma lei racista alemã, que privava da nacionalidade alemã os judeus emigrados, uma lei nula ab initio. Tal decisão foi estabelecida em uma demanda individual (havia elementos para demonstrar tanto a legalidade, quanto a eficácia social para outros indivíduos), mas se optou por considerar a nulidade total e $a b$ initio da lei, sob o fundamento de que: "O direito e a justiça não estão à disposição do legislador. [...] o Tribunal Constitucional Federal afirmou a possibilidade de negar aos dispositivos 'jurídicos' nacional-socialistas sua validade como direito." Para o Tribunal, "[...] contrariam os princípios fundamentais da justiça, de maneira tão evidente que o juiz que pretendesse aplicá-los ou reconhecer seus efeitos estaria pronunciando a injustiça, e não o direito (BVerfGE 3, 58 (119); 6, 132 (198)). Entretanto, certamente há uma interrogação: qual o limite da "especificidade" na aplicação do direito que o tornará (in)justo sob a perspectiva do casuísmo? A construção discursiva, incompleta ou inadequada, pode levar a um resultado supostamente adequado e, sob a perspectiva de correção, racional e justo, mas que em essência pode ser apenas uma construção retórica distorcida?

Da conclusão sobre essas interrogações, poder-se-á reforçar ainda mais o interesse pela aferição de uma base racional das decisões judiciais. Aliás, as teorias

\footnotetext{
4 ALEXY, Robert. Conceito e Validade do Direito. Tradução Gercélia Batista de Oliveira Mendes. São Paulo: Martins Fontes, 2011.

5 ALEXY, Robert. Conceito e Validade do Direito. 2011, p. 6-7.
} 


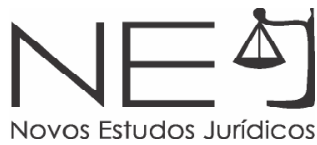

de Direito que transitam no espaço de construção argumentativa axiológica própria do pós-positivismo sofrem mais esse risco/perigo ao se tropicalizarem. Este processo pode afastar pressupostos democráticos, prejudicar a concretização de direitos fundamentais e os valores em construção próprios a nossa sociedade, provocando o reforço de estruturas de poder, tais como o alegado monopólio interpretativo avocado pelo Supremo Tribunal Federal em fundamentação de decisão ${ }^{6}$. Com isso, pode ser pavimentado o caminho para um incremento do ativismo judicial casuísta.

O limite é tênue, porém existente e identificável. Para tanto, há um caminho que pode ter a contribuição da argumentação jurídica. Primeiramente, é importante ter claro que direito e argumentação jurídica não são conceitos sinônimos ou sobrepostos. Para demostrar isto é interessante um raciocínio ${ }^{7}$, com recurso a uma analogia matemática: dentro da lógica matemática, há as chamadas condições necessárias e suficientes. As condições necessárias e suficientes impõem uma obrigatoriedade lógica, conferem um elevado grau de segurança e permitem o estabelecimento de relações de identidade. É possível identificar que algumas definições (D) têm certas características necessárias (CN) e que algumas características são próprias e exclusivas de algumas definições, isto é, são suficientes (CS). A matemática explica se CN é condição necessária para que algo $(X)$ seja uma definição $(D)$; então, se $(X)$ não for $(C N)$, necessariamente não será $(D)$ e se $(X)$ for $(D)$, necessariamente $(X)$ será $(C N)$. Dentro do mesmo raciocínio, se (CS) é condição suficiente para que algo $(X)$ seja uma definição $(D)$, então se $(X)$ for (CS) será (D). Esse raciocínio é fundamental para a compreensão da existência de uma relação de identidade. Uma opção de divisão de perspectivas de compreensão sobre o direito poderia ser a seguinte: entendê-lo pelo estudo das normas ' $\mathrm{p} 1^{\prime}$; como uma prática dos operadores do direito ' $\mathrm{p2}$ ' ou pelo ideal de Direito/visão crítica 'p3'. Contudo, de pronto, haveria uma dificuldade a uma resposta a um exercício lógico de suficiência ou necessidade, onde ' $q$ ' seria:

6 Decisão que deliberou sobre extensão dos efeitos da união civil à união homoafetiva.

7 Já foi apresentado isto, detalhadamente, no artigo intitulado: Decidir e argumentar: racionalidade discursiva e a função central do argumento, publicado na Revista da Faculdade de Direito da UFPR, vol. 61, n.3, 2016, DOI: http://dx.doi.org/10.5380/rfdufpr.v61i3.46712. 
permite a compreensão do direito. Tal exercício apresenta especiais dificuldades a uma precisão no seu conceito. Se, contemporaneamente, é consenso que as preocupações conceituais estão minimizadas, a simples aplicação da "prova real" desse raciocínio apontaria para uma dificuldade de delimitação do universo do direito a ser compreendido (p1, p2 ou p3) - essa uma preocupação importante atualmente. A perspectiva da argumentação jurídica leva isso em conta, sem excluir as perspectivas apontadas anteriormente e - igualmente - sem pretensão de identidade entre direito e argumentação jurídica, mas certa de que há uma inegável demanda deliberativa ao direito.

Nesse sentido, Atienza ${ }^{8}$ enumera cinco motivos do aumento da preocupação dos juristas com aspectos argumentativos da prática jurídica. São eles: 1) as teorias de direito mais marcantes do século XX deixaram, por razões diversas, de cuidar dessa sua dimensão; 2) a prática do direito parece consistir de modo relevante na argumentação $^{9}()$; 3) a constitucionalização do direito e outras mudanças nos sistemas jurídicos contemporâneos, que parecem levar a crescimento qualitativo e quantitativo em termos de exigência de fundamentação e argumentação das decisões dos órgãos públicos; 4) um ensino do direito mais prático teria que estar voltado ao manejo essencialmente argumentativo do material jurídico; e 5) na sociedade contemporânea, percebe-se uma perda da importância da autoridade e da tradição como fontes de legitimidade do poder e, em seu lugar, impondose a aceitação e o consentimento dos afetados; a democracia, sobretudo a democracia deliberativa, exige cidadãos capazes de argumentar racionalmente e competentemente em relação a ações e decisões.

Por outro lado, não é possível construir uma teoria da argumentação jurídica que cumpra suas funções teórica e prática, sem uma adequada análise estrutural do direito, Atienza ${ }^{10}$, especialmente compreendendo a vinculação dos processos argumentativos com o comportamento dos juízes. As relações entre o julgamento jurídico propriamente dito e os julgamentos de natureza moral ou política, bem como os elementos ideológicos e de poder, certamente

$8 \quad$ ATIENZA, Manuel. Curso de Argumentación Jurídica. Madrid: Trotta, 2013.

9 Atienza aponta para as imagens mais populares da prática jurídica, como o desenvolvimento dos julgamentos, nos quais é cada vez mais relevante a dimensão argumentativa.

10 ATIENZA, Manuel. EI Derecho como argumentación: concepciones de la argumentación. Barcelona: Editora Ariel, 2006. 
podem se manifestar no julgamento.

Assim, o risco da irracionalidade é real no processo da decisão judicial. Ao se projetar o processo decisório somente ao elemento íntimo do jurista julgador, estar-se-ia contrariando toda a construção arquitetada ao Estado de Direito, bem como, profundamente, arriscando um modelo constitucional de proteção aos direitos fundamentais. Parece razoavelmente clara a existência desse diagnóstico para as teorias procedimentais e substanciais, com forte relevância ao caso concreto. Assim é também central a busca em não se fundamentar o casuísmo.

Esta gestão de risco ocorre tanto na produção como na aplicação do direito, quando a argumentação jurídica tem um papel de destaque, cujo entendimento vai além de um exercício sobre a lógica jurídica ${ }^{11}$. Tendo isso em mente, é importante a constatação que a compreensão argumentativa possibilita o entendimento de muitos aspectos do próprio direito dos Estados constitucionais ${ }^{12}$.

Também é importante fixar delimitar que a compreensão teórica da argumentação jurídica e sua relação com o direito estará voltada à decisão judicial. Isso tem diversas formas de se justificar. Elege-se como mais relevante o contexto atual de importância e de centralidade que o conjunto de decisões judiciais tem dado na interpretação do direito. A judicialização do direito ${ }^{13}$ pode ser descrita como um fenômeno real e, teleologicamente, para a compreensão do direito, muito acentuado. Assim, dentro da compreensão da decisão judicial, destacam-se dois contextos: contexto de descoberta e contexto de justificação. O primeiro se refere a estágios de opção decisória [tomada de decisão], cuja compreensão facilmente se afastaria dos modelos teóricos aqui trabalhados.

11 É possível a verificação de inúmeros significados para lógica jurídica, inclusive a qualificação dada a algo juridicamente racional e fundamentado. Assim, pode-se abordar o tema por muitas formas. Por lógica, optou-se por entender argumentar com encadeamento de enunciados, que a partir de premissas chega-se a uma conclusão necessária. Não é nesse limite que se trabalhará com a teoria da argumentação jurídica.

12 ATIENZA, Manuel. EI Derecho como argumentación: concepciones de la argumentación. p.11.

13 Werneck Vianna faz uma interessante distinção de dois eixos teóricos sobre o assunto: substancialistas e procedimentalistas. Ambos basicamente discordam sobre os efeitos da judicialização sob a ótica da práxis democrática e incremento da cidadania, mas deve ser feita a constatação que, boa ou ruim, a judicialização do Direito é um fenômeno. É possível também um distinção entre as expressões judicialização do Direito e judicialização da Política. Embora seja comum essa distinção, entende-se de pouca relevância, dada a visão argumentativa do Direito. Assim, no campo do Direito e da Política [se é que se poderia repartir o campo], há um exercício prático de argumentação em busca do convencimento, ambos com vistas a uma estabilização das opções decisórias. VIANNA, Luiz Werneck. A judicialização da política e das relações sociais no Brasil. Rio de Janeiro: Renavan, 1999. 
Fatores psicológico-existenciais, ideológicos, econômicos, religiosos, morais ${ }^{14}$ podem levar a uma opção decisória. Algumas importantes pesquisas multi/ transdisciplinares estão sendo feitas nesta área árida ao jurista. Para o presente trabalho deste contexto, reforça-se a confiança de que o processo de tomada de decisão é muito mais complexo ${ }^{15}$, profundo, obscuro, labiríntico e multímodo, do que o diagnosticado por terapêuticas hermenêuticas. Tômbola! O segundo (justificação) demanda ao emissor da decisão a fundamentação da sua opção decisória. Nesse momento, é que se buscará, pela compreensão das contribuições da argumentação jurídica, a possibilidade de, procedimentalmente, apontar as inconsistências e as incorreções [irracionalidades] da opção tomada.

Para se fazer conexão desses elementos e uma concepção dinâmica do Direito, deve-se partir da noção de conflito, posto que o conflito e a necessidade de seu encaminhamento podem explicar a importância do Direito. Nesse aspecto, o Direito pode ser visto como um instrumento de tratamento de problemas de certo tipo (obviamente nem sempre se chegando a uma solução). A tomada de decisão em relação aos conflitos tem que estar sustentada por razões de certo tipo, por argumentos.

Assim, o Direito pode ser visto como uma complexa instituição voltada ao tratamento de conflitos por meio de argumentos. Um juiz encarregado de decidir um conflito argumenta. De uma maneira geral, a criação, a interpretação e a aplicação do Direito são experiências argumentativas. Assim, parece, novamente, indissociável ao Direito seguir sua construção amparado em uma teoria da argumentação. Segundo Atienza, a argumentação é um procedimento de resolução de problemas, estabelecendo soluções para problemas e para tal apontando razões. Assim, a argumentação é uma atividade com forte caráter instrumental, pois faz a mediação entre dois extremos. De um lado um problema e de outro lado a solução. $O$

14 Aqui os fatores morais não são aqueles procedimentalmente construídos dentro de um universo histórico e social.

15 Isto converge com pensamento lastreada em Dworkin, que um viés no positivismo jurídico amparado na pretensão de segurança tem problemas sérios. Segundo condensa Dias, "A discricionariedade judicial - um dos cânones do pensamento positivo -, para decidir casos que não atraem diretamente os conceitos dispositivos, não pode ser levada a sério (para usar a linguagem do próprio autor [Dworkin] em outra obra que auxilia a compreensão da presente análise." DIAS, Jean Carlos. Refutações às críticas à tese da resposta certa a partir da abordagem sistêmica do pensamento Dworkiniano. Revista Novos Estudos Jurídicos/UNIVALI. Volume $22-N^{\circ} 2-2^{\circ}$ Quadrimestre de 2017. DOI: http://dx.doi.org/10.14210/nej.v22n2.p385-389. 


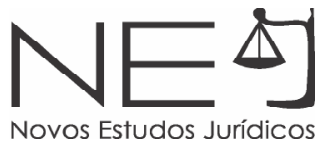

final da argumentação é um enunciado diretivo. ${ }^{16} \mathrm{E}$ como se qualifica a racionalidade nessa relação? Ao escrever Practical Reason in Law and Morality (PRLM) como parte do quarteto cujo tema é Direito, Estado e Razão prática, MacCormick ${ }^{17}$ dedicouse a compreender questões sobre a autonomia de pessoas como agentes morais; a razão universal, frente ao particularismo dos julgamentos morais e a estrutura objetiva que atende às tentativas de o homem apontar bons motivos para decidir o que fazer frente a sérios dilemas práticos.

MacCormick ${ }^{18}$ pergunta-se se a razão pode ser prática e afirma que a resposta de David Hume seria que a razão é escrava das paixões, e que toda motivação de ação para o homem vem da emoção e dos sentimentos. Se alguém se sente agradecido por algo recebido fará nascer o desejo de algo bom em retorno. O raciocínio sobre questões de fato pode ajudar a encontrar o melhor jeito de agradecer um favor recíproco. A razão, porém, entra apenas para preencher a vontade estabelecida, baseada no sentimento de gratidão.

MacCormick ${ }^{19}$ entende, por outro lado, que a conduta humana envolve razão e emoção. A boa e sábia ação se dá por meio de boas razões e o equilíbrio entre a natureza afetiva e intelectual. O tempero entre a linha do sentimentalismo e a racionalização sem sentido crítico pode ser um campo muito importante para a estruturação de boas razões. Um ponto central no seu livro está o objetivo de alcançar uma síntese acreditada do pensamento de Kant e de Adam Smith. Com isso seria possível resolver o enigma da razão prática. Esclarece que tanto o sistema de liberdade natural de Smith quanto as leis de liberdade de Kant são inadequadas para satisfazer completamente as demandas de justiça contemporâneas. Instrumentalizando essa busca, MacCormick ${ }^{20}$ passa a analisar o que chama "o imperativo categórico de Smith", isto é, uma reconstrução do princípio estrutural básico do pensamento moral, desenvolvido por Kant, em função da necessidade de dar a devida importância ao sentimento humano e emoção em qualquer juízo sobre como agir em impasses.

16 ATIENZA, Manuel. Curso de Argumentación Jurídica. Madrid: Trotta, 2013. p. 643.

17 MACCORMICK, Neil. Retórica e Estado de direito. Trad. Conrado Hübner Mendes. Rio de Janeiro: Elsevier, 2008.

18 MACCORMICK, Neil. Practical Reason in Law and Morality. Oxford: Oxford University Press, 2011.

19 MACCORMICK, Neil. Practical Reason in Law and Morality. 2011.

20 MACCORMICK, Neil. Practical Reason in Law and Morality. 2011, p.2. 
Como a ideia de razão prática também não pode estar dissociada da capacidade de autocomando ou autogoverno das pessoas, a reflexão sobre autonomia também é objeto de MacCormick ${ }^{21}$. Segundo ele, para Kant existe uma transcendental pressuposição de nossa capacidade para se conduzir no mundo; o homem age subjetivamente, na medida em que de alguma forma encontra regras para conduzir. Contudo, o homem não age simplesmente, mas por alguma consequência. "Como as marés são puxadas pela gravidade, ou animais selvagens pelo instinto, o homem também se vê envolvido em processos causais sobre os quais não tem muito controle", sintetizou. Se o homem é livre, a importância da discussão também sobre o bom uso da liberdade. Assim, se o homem é livre, quer fazer suas escolhas e, por isso, quer ter alguma ideia do que é o bom e sobre o que o fará virtuoso. Conclui que, a fim de cultivar o bem, deve-se buscar o que é bom.

Para tanto, então, MacCormick ${ }^{22}$ entende que o julgamento final sobre uma questão é certo ou errado, de acordo com o conjunto discursivo que se deu por completo. Tanto os chamados legal judgements quanto os moral judgements envolvem formas de razão prática. Contudo, há nos primeiros um anteparo mais institucionalizado que nos últimos. Aí um elemento que demanda uma boa fundamentação para as decisões apoiadas em julgamentos morais. Alerta para as pessoas avocadas de autoridade e o risco de suas decisões. Ao relembrar o rei francês Luís XV a falar ao seu povo 'Après moi le déluge' ou Hobbes - 'grant absolute sovereignty or put up with the war of all against all', reafirma o papel central da razão em refutar o absolutismo da autoridade, a autoridade formalmente em si, como licença à arbitrariedade na imposição de condutas e pensamentos. As decisões moralmente orientadas devem ser produto de uma natureza humana madura e orientada. Pessoas que agem e vivem de acordo com a razão não ignoram, segundo ele, a dimensão sentimental da vida humana, mas passam através das paixões. Isso será fundamental para se enfrentarem alguns desafios postos à Argumentação Jurídica para a definição de condições de precedência em um sopesamento. ${ }^{23}$

Para ele, o Direito é uma disciplina retórica, mas não só retórica, na medida da construção e da estruturação de argumentos lógicos de persuasão. Pode existir

$21 \quad$ MACCORMICK, Neil. Practical Reason in Law and Morality. 2011.

22 MACCORMICK, Neil. Practical Reason in Law and Morality. 2011, p.172.

23 MACCORMICK, Neil. Practical Reason in Law and Morality. 2011. p. 172-173. 
um lado obscuro, na escolha em uma decisão judicial e, nesse momento, se há alguma possibilidade de proteção, está na análise das razões que justificaram a decisão. Percebe-se, portanto, até mesmo em uma tradição distinta da brasileira, que não se pode ignorar que, ao decidir, busca-se também persuadir. Se a persuasão se dissocia da justificação, há o risco retórico. Esta retórica "divergente" [da justificação] que fortemente estigmatiza as decisões judiciais brasileiras, quando vista em seu conjunto.

No entender de Alexy $^{24}$, a racionalidade na fundamentação jurídica sempre encontrou dificuldades por raciocínios muito extremos. De um lado, variantes subjetivistas, relativistas, decisionistas ou irracionalistas e, de outro, objetivistas, absolutistas, cognocistivistas ou racionalistas, mas sempre na lógica do "tudo ou nada". Afirma ainda que não são possíveis teorias morais materiais que, para cada questão prática, permitam extrair uma resposta, mas são possíveis teorias morais procedimentais que formulem regras ou condições de argumentação para uma decisão prática racional. Assim, com um sistema de regras e princípios do discurso (propõe um conjunto de regras e formas de argumentar), será assegurada a racionalidade da argumentação e de seu resultado. Consequentemente, numa espécie de codificação de posturas, a razão prática pode ser complementada com regras específicas do discurso jurídico. Nisso está a base para a justificação e crítica das decisões e do sistema jurídico em seu conjunto. ${ }^{25}$

Esse estabelecimento procedimental visa garantir uma resposta ao problema sério do casuísmo nas decisões judiciais, algo grave que afeta o aspecto de correção a que o Direito não positivista deve estar conectado. Outro problema conceitual posto ao Direito é a sua relação com a Argumentação Jurídica e o modelo constitucional baseado nos pré-compromissos e regras preestabelecidas.

\section{REGRAS DO JOGO PREESTABELECIDAS E A ARGUMENTAÇÃO JURÍDICA.}

Os processos históricos revolucionários de uma forma geral mostram (e o que estruturou o constitucionalismo não foi diferente) que: em um primeiro momento, a revolução e sua ideia vencedora veem o futuro apenas como o

24 ALEXY, Robert. Sistema jurídico, princípios y razón práctica. Tradução de Manuel Atienza. DOXA 5. 1988, p. 149150.

25 ALEXY, Robert. Sistema jurídico, princípios y razón práctica. Tradução de Manuel Atienza. DOXA 5. 1988, p.150. 
momento de colheita dos "bons" frutos da semente revolucionária. Contudo, o Tempo muitas vezes é cruel! Um xeque foi feito ao constitucionalismo, isto é, nas palavras de Stephen Holmes ${ }^{26}$, "[...] Cómo se puede reconciliar 'el consenstimiento de los gobernados' con la garantia de un consentimento ulterior mediante una convención constitucional?" Por que algo que foi elaborado por uma geração deve exercer tamanho poder sobre as próximas? Como fica a soberania popular? Não seria um paradoxo ver que o constitucionalismo é antidemocrático, na medida em que se afastam certas decisões do processo democrático? Por que se deve conferir a uma geração a deliberação plena (compromissos constitucionais) e a outras uma deliberação restrita?

Os fundamentos para uma ideia de pré-compromisso constitucional autorizam que homens se permitam indiretamente comprometer outros por meio de obrigações, para que, em essência teleológica, alcancem os objetivos da sociedade e, em última análise, haja benefício para a própria sociedade ao longo do Tempo. Em resumo, " [...] al aceptar una Constitución preestabelecida, un Pueblo se ata sus propias manos, pero también se libera de cargas considerables." 27

Mas as justificativas do pré-compromisso prolongam o paradoxo, com uma contradição prática: a vontade de ceder à vontade. Disso vem a pergunta: para conservar a liberdade de vontade, deve se restringir a ela própria (vontade)? Embora o debate possa seguir em outra direção, essa redução quase molecular do problema do pré-compromisso constitucional permite identificar uma necessária preocupação, pois não se pode fugir da ideia de que esse dilema é uma construção humana e demanda uma deliberação. Assim, qual(is) a(s) forma(s) correta(s) de se comportar, já que as escolhas serão decisões complexas, e como justificá-las?

Nesse sentido, o diálogo entre as teorias institucionalistas e a argumentação jurídica não só é possível como potencialmente rico, pois elas enfrentam um problema semelhante. A tensão entre constitucionalismo e democracia, reconhecidamente um ponto de debate para os teóricos do pensamento político, é um ponto precioso, portanto, para o diálogo do constitucionalismo

26 HOLMES, Stephen. Constitucionalismo y democracia. Tradução: Monica Utrilla de Neira. Ciudad de Mexico: Fondo de Cultura Económica, 1999. p. 217.

27 HOLMES, Stephen. Constitucionalismo y democracia. Tradução: Monica Utrilla de Neira. Ciudad de Mexico: Fondo de Cultura Económica, 1999. p. 244. 
com a argumentação jurídica, posto que a linguagem apresenta possibilidades de interface com as alterações de características do homem e suas instituições sob efeito do tempo.

Dentro das opções institucionais, o neoconstitucionalismo ${ }^{28}$ surge como termo diferenciador de um conjunto de movimentos que buscam uma Teoria do Direito capaz de refletir as transformações ocasionadas nas relações humanas pela constatação desse novo momento diferenciado de compreender o Direito.

Para Figueroa, ${ }^{29}$ em uma compreensão da visão constitucional concorreram alguns aspectos: material, estrutural, funcional e político. Pelo aspecto material, houve a recepção pelo sistema jurídico de demandas da moral crítica, com forte carga axiológica, levando o Direito a um processo de rematerialização. Tal aspecto material leva a considerar que, diferentemente do constitucionalismo erguido sobre uma ideologia, converteu-se em uma teoria do Direito oposta ao positivismo jurídico como método. Enquanto isso, sob o aspecto estrutural, a constitucionalização do ordenamento tem relação com a estrutura das normas constitucionais; já o aspecto funcional relaciona-se ao tipo de argumentação que essas fomentam, isto é, os princípios constitucionais.

Sob esse aspecto funcional está a ponderação, como forma de se aplicar o Direito [afastando-se o casuísmo], sujeito à expansão do âmbito de influência que possuem os princípios constitucionais, que remete a uma teoria de Argumentação Jurídica, nas palavras de Figueroa: "[...] a conhecida 'tese do caso especial' [...]."

De uma maneira geral, compromissos constitucionais estão estruturados e refletem tanto uma perspectiva axiológica quanto deontológica. Também, de uma maneira geral, as demandas deliberativas que possam afetar tais compromissos podem se apresentar de maneira complexa, e aqui a ética discursiva tem um papel como nas soluções de dilemas jurídico-morais, e o argumento posição relevante.

28 Não se tem a pretensão no presente trabalho de se avaliar se o termo neoconstitucionalismo é adequado ou se é a melhor expressão de uma corrente institucionalista. Comanducci apresenta um duplo significado ao termo neoconstitucionalismo. Em um primeiro, o de uma teoria e/ou ideologia e/ou método de análise do Direito. Um segundo, como alguns elementos estruturais de um sistema jurídico e político. COMANDUCCI, Paolo. Formas de (Neo)Constitucionalismo: una análisis metateórica. In: CARBONELL, Miguel. Neoconstitucionalismo(s). 2005. p. 75.

29 FIGUEROA, Alfonso. La teoria del Derecho en tempos del constitucionalismo. In CARBONELL, Miguel. Neoconstitucionalismo(s). 2005, p. 165.

30 "[...] la conocida como 'tesis del caso especial' [...]." FIGUEROA, Alfonso. Neoconstitucionalismo(s). 2005. p. 166. Tradução nossa. 
Como identificado pelos teóricos do direito mencionados no texto, há uma vinculação entre os processos argumentativos e o comportamento dos juízes. Os limites de interferência judicial, especialmente quando se trata de decisões de conteúdo fortemente político, demostram que o problema é complexo e importante para o direito. Percebe-se que há compatibilidade entre os elementos de fundamentação do Estados constitucionais com as possibilidades procedimentais da argumentação jurídica à disposição para a decisão judicial. Neste mesmo sentido, compõe o problema o elemento hermenêutico que carrega a atuação dos juízes, que faz reforçar a importância de uma resposta sobre os limites da especificidade possível para a aplicação do direito em uma decisão judicial.

O encaminhamento das questões anteriormente apontadas passa pela perspectiva da argumentação jurídica de uma dimensão prática do direito. Dentro dessa perspectiva, os limites da especificidade serão apontados dentro de uma ótica de correção. Dentro da ótica de correção, a justificativa decisória deverá identificar condições concretas de precedência argumentativamente consistentes e coerentes. Com isso, dentro da perspectiva prática da argumentação, se o contexto de descoberta judicial é relativamente pouco controlável, o contexto subsequente, de justificação, imporia uma série de procedimentos que retirariam a força de uma hermenêutica própria.

Há o risco retórico, sem dúvidas (a realidade mostra!), mas dentro de uma dimensão pragmática, ao se oferecer critérios procedimentais aferíveis de adequação das premissas e das conclusões expostas na decisão permite-se, objetivo de segurança substancial.

\section{REFERÊNCIAS DAS FONTES CITADAS}

ALEXY, Robert. Teoria de La argumentación jurídica. Tradução de Manuel Atienza e Isabel Espejo. 2. ed. Madrid: Centro de Estudos Políticos y Constitucionales, 2007.

ALEXY, Robert. Teoria dos Direitos Fundamentais. Tradução de Virgílio Afonso da Silva. 5. ed. alemã, São Paulo: Malheiros, 2008. 
ALEXY, Robert. Teoria dos Direitos Fundamentais. Tradução de Virgílio Afonso da Silva. 5 ed. alemã, 2. ed. brasileira, São Paulo: Malheiros, 2015.

ALEXY, Robert. Sistema jurídico, princípios y razón práctica. Tradução de Manuel Atienza. DOXA 5. 1988.

ALEXY, Robert. Constitutional Rights and Proportionality. Revus [Online], 22 - 2014, Online since 25 June 2014, connection on 08 July 2014. Disponível em: http://revus.revues.org/2783; DOI: $10.4000 /$ revus.2783. Acesso em: 12/02/2015.

ALEXY, Robert. The argument from Injustice. A reply to Legal Positivism. Translated by Bonnie Litschewski Pauson and Stanley L. Paulson. Oxford. : Oxford University Press, 2010.

ALEXY, Robert. Conceito e Validade do Direito. Tradução Gercélia Batista de Oliveira Mendes. São Paulo: Martins Fontes, 2011.

ATIENZA, Manuel. As Razões do Direito. Teorias da Argumentação Jurídica. Tradução de Maria Cristina Guimarães Cupertino. São Paulo: Landy, 2002.

ATIENZA, Manuel. El Derecho como argumentación: concepciones de la argumentación. Barcelona: Editora Ariel, 2006.

ATIENZA, Manuel. Curso de Argumentación Jurídica. Madrid: Trotta, 2013.

CAVALCANTI, Ana Beatriz Vanzoff Robalinho; MACHADO, Bruno Amaral. _ Democracia e os paradoxos da judicialização das políticas públicas de saúde no Brasil. Revista Novos Estudos Jurídicos/UNIVALI. Volume 22 - No 2 - 20 Quadrimestre de 2017. DOI: http://dx.doi. org/10.14210/nej.v22n2.p624-652.

COMANDUCCI, Paolo. Formas de (Neo)Constitucionalismo: una análisis metateórica. In CARBONELL, Miguel. Neoconstitucionalismo(s). 2005.

DIAS, Jean Carlos. Refutações às críticas à tese da resposta certa a partir da abordagem sistêmica do pensamento Dworkiniano. Revista Novos Estudos Jurídicos/UNIVALI. Volume 22 - No 2 - 2o Quadrimestre de 2017. DOI: http://dx.doi.org/10.14210/nej.v22n2.p385-389

GÜNTHER, KLAUS. Teoria da argumentação no direito e na moral: justificação e aplicação. Tradução Claudio Molz. 2 ed. Rio de Janeiro: Forense, 2011.

HOLMES, Stephen. Constitucionalismo y democracia. Tradução: Monica Utrilla de Neira. Ciudad de Mexico: Fondo de Cultura Económica, 1999.

MACCORMICK, Neil. Argumentação jurídica e teoria do direito. Tradução Waldéa Barcellos. São Paulo: Martins Fontes, 2006.

MACCORMICK, Neil. Retórica e Estado de direito. Trad. Conrado Hübner Mendes. Rio de Janeiro: Elsevier, 2008. 
MACCORMICK, Neil. Practical Reason in Law and Morality. Oxford: Oxford University Press, 2011.

MARTINS, Argemiro C. M.; ROESLER, Claudia R.; e JESUS, Ricardo A.R. A noção de coerência na teoria da argumentação jurídica de Neil MacCormick: caracterização, limitações, possibilidades. Revista Novos Estudos Jurídicos/UNIVALI, volume 16, n. 2, mai-ago 2011, p.207-221.

VIANNA, Luiz Werneck. A judicialização da política e das relações sociais no Brasil. Rio de Janeiro: Renavan, 1999.

Recebido em: 04/07/2018

Aprovado em: 22/04/2018

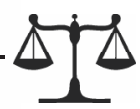

